\title{
The interplay of polyoxyethylene (40) stearate surfactant concentration and aging time on the Mesoporous $\gamma$-alumina synthesis and appraisal of its catalytic activity
}

\author{
Abdu Muhammad Bello ${ }^{1}$ (D) Abdul Rahim Yacob ${ }^{2}$ \\ Received: 25 September 2020 / Accepted: 28 December 2020 / Published online: 8 January 2021 \\ (c) The Author(s) 2021 OPEN
}

\begin{abstract}
An economical and environmentally benign synthesis method remains important in industrial processes. In this work, kaolin an abundant and non-toxic precursor is employed for mesoporous gamma-alumina synthesis. The study explored the consequence of varying polyoxyethylene (40) stearate (PS) surfactant concentration and aging time in the synthesis of mesoporous gamma-alumina with enhancing structural properties. The alumina was characterized using X-Ray Powder Diffraction (XRD), Thermogravimetric-Derivative Thermal Gravimetric (TG-DTG), Fourier Transform Infrared (FTIR), $\mathrm{N}_{2}$ Adsorption-Desorption, Field Emission Scanning Electron Microscopy (FESEM), Solid State ${ }^{27}$ AI MAS NMR, and X-Ray Fluorescence (XRF). Structural properties and morphology of the mesoporous $\gamma-\mathrm{Al}_{2} \mathrm{O}_{3}$ improved with increasing surfactant amount from $0.45 \mathrm{~g}$ to $1.8 \mathrm{~g}$ and aging time from 1 to 2 days, then dropped afterward. Accordingly, mesoporous $\mathrm{Y}-\mathrm{Al}_{2} \mathrm{O}_{3}$ synthesized with $1.8 \mathrm{~g}$ PS and age for 2 days (Al-1.8-2) possessed the highest surface area of $319.2 \mathrm{~m} / \mathrm{g}$, a narrow average pore diameter of $2.7 \mathrm{~nm}$, and pore volume of $0.42 \mathrm{~cm}^{3} / \mathrm{g}$. Thus, Al-1.8-2 was chosen and doped with $15 \%$ $\mathrm{NaOH}$ to obtained 15- Na/Al-1.8-2 catalyst. After modification, the basic sites increased, the surface area decreased, and the morphology changed, signifying Na incorporation into the alumina. On application in methanolysis reaction, up to $99.46 \%$ biodiesel yield was obtained, demonstrating a very high activity for the catalyst. The tremendous activity of the catalyst can be associated with the enhanced structural properties of the mesostructured gamma-alumina.
\end{abstract}

Keywords Alumina $\cdot$ Catalytic activity $\cdot$ Aging time $\cdot$ Concentration $\cdot$ Surfactant

\section{Introduction}

The quest for mesoporous materials synthesis traced its origin to the successes recorded by zeolites materials and the subsequent need to improve on that. Despite these successes, microporosity impedes the applications of zeolites in areas where mesoporosity is essential. After so many attempts zeolite with mesoporous structure was successfully synthesized in the presence of larger template molecules, however with poor stability [27]. Motivated by the mesoporous zeolite synthesis, Mobil researchers synthesized a family of ordered mesoporous materials (M41S) in 1992 by polymerizing Si and Al precursors around supramolecular assemblies of molecules template [30]. The M41S materials have attracted the attention of materials scientists due to their high surface area (around $1000 \mathrm{~m}^{2} / \mathrm{g}$ ) and narrow pore size distribution with longrange order $[7,30]$. Consequently, great efforts have been initiated to synthesize similar materials, like alumina [13, 14].

However, the efforts to synthesized organized mesoporous alumina were fruitless due to the high

$\triangle$ Abdu Muhammad Bello, muhbaf70@yahoo.com | ${ }^{1}$ Department of Chemistry, Faculty of Science, Kano University of Science and Technology Wudil, PMB 3244, Kano, Kano State, Nigeria. ${ }^{2}$ Department of Chemistry, Faculty of Science, University of Technology Malaysia, UTM , 81310 Skudai, Johor, Malaysia. 
reactivity associated with the lower electronegativity of alumina and its ability to exhibit several coordination states. The high reactivity leads to an uncontrolled condensation resulting in macroscopic phase segregation in the alumina. Another factor obstructing the synthesis of organized mesoporous alumina is the fact that the crystallization energies of metal oxides usually tend to stabilize the inorganic-inorganic interface and disrupt the establishment of a curved surface of ordered mesostructure, ensuing poor crystallinity [5]. Nevertheless, after several modifications of the original synthesis approach for the M41S materials, organized mesoporous alumina was successfully synthesized by the end of the twentieth century [28].

Large-scale production of alumina generally utilizes boehmite $(\mathrm{AlOOH})$ or gibbsite $\left(\mathrm{Al}(\mathrm{OH})_{3}\right)$ as precursors. Dehydrating the precursor at high temperatures resulted in a series of polymorphic transitions as presented in Eq. 1. and PEG-4500 surfactant. The Nano $\gamma$-alumina has a spherical shape, with a surface area of $201.53 \mathrm{~m}^{2} / \mathrm{g}$ and small particle size distribution between 22 to $36 \mathrm{~nm}$. In another study, Nano-sized activated alumina was successfully synthesized from kaolin via an innovative three-step method. The as-synthesized activated alumina possessed a similar XRD pattern as for the commercial activated gamma-phase alumina. The aluminium oxide content of the as-synthesized sample was $83.47 \mathrm{wt} . \%$ while that of the commercial sample was $90.22 \mathrm{wt} . \%$. The microporous as-synthesized activated alumina has a high surface area of $202.3 \mathrm{~m}^{2} / \mathrm{g}$, a pore diameter of $1.212 \mathrm{~nm}$, a pore volume of $0.0613 \mathrm{~cm}^{3} / \mathrm{g}$, with a nano-size structural morphology and a crystal size of $12.5 \mathrm{~nm}$ [35].

In this study, copiously available kaolin is utilized as a raw material for the alumina synthesis, making the process inexpensive and environmentally friendly. Besides, the

$\mathrm{AlOOH} \stackrel{300 o_{c}}{\longrightarrow} \eta-\mathrm{Al}_{2} \mathrm{O}_{3} \stackrel{450 o_{\mathrm{c}}}{\longrightarrow} \gamma-\mathrm{Al}_{2} \mathrm{O}_{3} \stackrel{900 o_{\mathrm{c}}}{\longrightarrow} \delta-\mathrm{Al}_{2} \mathrm{O}_{3} \stackrel{1000 o_{\mathrm{c}}}{\longrightarrow} \theta-\mathrm{Al}_{2} \mathrm{O}_{3} \stackrel{1200 o_{\mathrm{c}}}{\longrightarrow} \alpha-\mathrm{Al}_{2} \mathrm{O}_{3}$

The boehmite and gibbsite are themselves intermediates in the production of alumina from raw minerals such as kaolin [36]. The synthesis of alumina from kaolin is by either (i) reacting the kaolin with a concentrated base solution to directly obtain alumina without the formation of the intermediate precursors, or (ii) by extracting the alumina phase from the kaolin crystal structure with a concentrated acid solution. But for the acid extraction, additional steps are required to recover the boehmite or gibbsite from the extract, and to convert it to alumina by calcination [36]. Although numerous studies are available on the synthesis of alumina from aluminium alkoxide and inorganic salts, only a few reports are available on the synthesis of alumina from kaolin.

In their work, Pan et al. [32] investigated the effect of the TX-100/ $\mathrm{Al}^{3+}$ ratio on the structural and textural properties of mesoporous $\mathrm{Y}^{-} \mathrm{Al}_{2} \mathrm{O}_{3}$ synthesized from calcined coal-series kaolin. Using the TX-100/ $\mathrm{Al}^{3+}$ ratio in the range of 0.03 to 0.15 , a surface area of 193.0 to $261.0 \mathrm{~m}^{2} / \mathrm{g}$ and a pore size of 5.04 to $6.71 \mathrm{~nm}$ were obtained. It was concluded that the amount of TX-100 significantly influenced the structure and porous properties of the mesoporous alumina. In a similar study, large mesoporous alumina with a specific surface area of $253.4 \mathrm{~m}^{2} / \mathrm{g}$, a large pore volume of $1.487 \mathrm{~cm}^{3} / \mathrm{g}$, and an average pore diameter of $12.9 \mathrm{~nm}$ was synthesized from coal-series kaolin in the presence of cetyltrimethylammonium bromide (CTAB) template at room temperature. The mesoporous alumina was found to possessed wormhole-like pores without a long-range ordered framework [31]. In their work, Darban et al. (2013) synthesized nano-mesoporous $\gamma$-alumina from kaolin using a precipitation method in the presence of ammonia by-product is silica an economically viable product. The reported synthesis of gamma-alumina from kaolin utilized surfactants other than polyoxyethylene (40) stearate and only a few reported varying the surfactant concentration, while none studied the effect of surfactant aging time on alumina properties. In addition to ordered mesoporosity, good crystallinity is crucial to improving catalytic activity and the adsorptive capacity of alumina. For this reason, the present study controls particle condensation as well as crystallization energy by varying surfactant concentrations and aging time. Finally, the alumina is modified with $\mathrm{NaOH}$ and employed in the methanolysis of corn oil to assess its catalytic activity.

\section{Experimental}

\subsection{Materials}

The kaolin was obtained from Getso town in Kano State, Nigeria. The hydrochloric acid and sodium hydroxide were purchased from QRëC ${ }^{\mathrm{TM}}$. While the polyoxyethylene (40) stearate [poly(oxy-1,2-ethanediyl), alpha-hydro-omegahydroxy-, octadecanoate] surfactant was supplied by Sigma. All reagents were of analytical grade and used without further purification. The polyoxyethylene (40) stearate henceforth will be referred to as PS.

\subsection{Synthesis of mesoporous alumina}

The kaolin was calcined into metakaolin in a programmable furnace at $750^{\circ} \mathrm{C}$ for $3 \mathrm{~h}$, at a heating rate of $5^{\circ} \mathrm{C} /$ 
min. The metakaolin was then leached with $6 \mathrm{M}$ hydrochloric acid (solid: liquid ratio $1: 5 \mathrm{~g} / \mathrm{mL}$ ) at $90{ }^{\circ} \mathrm{C}$ for $2.5 \mathrm{~h}$ under stirring at $836 \mathrm{rpm}$. An excess solution of $5 \mathrm{M} \mathrm{NaOH}$ was added to the filtered suspension to convert $\mathrm{Al}^{3+}$ into $\mathrm{NaAlO}_{2}$ and precipitate impurities like; $\mathrm{Fe}^{3+}, \mathrm{Mg}^{2+}$. Various concentrations of PS $(0.45,0.9,1.8,3.6$, or $4.5 \mathrm{~g}$ PS in $20 \mathrm{~mL}$ of water) were added to different solutions of the $\mathrm{NaAlO}_{2}$ and stirred for 30 min., then allowed to age for 1, 2, or 3 days as the case may be. The $\mathrm{pH}$ of the mixtures was then adjusted to 7 using $6 \mathrm{M} \mathrm{HCl}$ and $5 \mathrm{M} \mathrm{NaOH}$ solutions to precipitate boehmite. The precipitated boehmite was filtered, washed with deionized water, and dried at $110^{\circ} \mathrm{C}$, followed by calcination at $500^{\circ} \mathrm{C}$ for $4 \mathrm{~h}$. The obtained alumina is denoted $\mathrm{Al}-\mathrm{X}-\mathrm{Y}$, where $\mathrm{X}$ and $\mathrm{Y}$ are the $\mathrm{PS}$ amount and aging time, respectively. For instance, $\mathrm{Al}-0.45-1$ stands for alumina synthesized with $0.45 \mathrm{~g} \mathrm{PS}$ and aged for 1 day. The steps involved are expressed in Eqs. 2 to 6. The same procedure was followed to prepare another alumina without a surfactant addition for comparison. This alumina is denoted Al-500.

Step 1: Conversion of kaolin into metakaolin:

$$
\mathrm{Al}_{2} \mathrm{Si}_{2} \mathrm{O}_{5}(\mathrm{OH})_{4(\mathrm{~s})} \rightarrow \mathrm{Al}_{2} \mathrm{Si}_{2} \mathrm{O}_{7(\mathrm{~s})}+2 \mathrm{H}_{2} \mathrm{O}_{(\mathrm{g})}
$$

Step 2: Dealumination of metakaolin:

$$
\mathrm{Al}_{2} \mathrm{Si}_{2} \mathrm{O}_{7(\mathrm{~s})}+6 \mathrm{HCl}_{(\mathrm{aq})} \rightarrow 2 \mathrm{AlCl}_{3(\mathrm{aq})}+2 \mathrm{SiO}_{2(\mathrm{~s})}+3 \mathrm{H}_{2} \mathrm{O}_{(1)}
$$

Step 3: Precipitation of impurities:

$$
\mathrm{AlCl}_{3(\mathrm{aq})}+3 \mathrm{NaOHI}_{(\mathrm{aq})} \rightarrow \mathrm{NaAlO}_{2(\mathrm{aq})}+\mathrm{Fe}^{3+}+\mathrm{Mg}^{2+}
$$

Step 4: Addition of PS and Precipitation of boehmite

$\mathrm{NaAlO}_{2(\mathrm{aq})}+\mathrm{HCl}_{(\mathrm{aq})} \rightarrow \mathrm{AlOOH}_{(\mathrm{s})}+\mathrm{NaCl}_{(\mathrm{aq})}$

Step 5: Calcination of boehmite into gamma-alumina:

$$
\mathrm{AlOOH}_{(\mathrm{s})} \stackrel{\Delta}{\longrightarrow} \mathrm{Al}_{2} \mathrm{O}_{3(\mathrm{~s})}+\mathrm{H}_{2} \mathrm{O}_{(\mathrm{g})}
$$

\subsection{Catalyst preparation}

The catalyst was prepared by doping $0.3 \mathrm{~g} \mathrm{NaOH}$ on $2 \mathrm{~g}$ mesoporous $\gamma$-alumina using wet impregnation method, then dried overnight at $120^{\circ} \mathrm{C}$, and calcined at $500^{\circ} \mathrm{C}$ to obtained 15-Na/Al-1.8-2.

\subsection{Characterization}

Structural phase analysis was carried out on a Bruker D8 having Siemens Diffractometer D5000 with Cu-Ka radiation ( $40 \mathrm{kV}, 40 \mathrm{~mA}, \lambda=1.5406 \AA$ ) (USA). The TG-DTA analysis was conducted using Perkin Elmer Simultaneous Thermal Analyzer (STA 8000) (USA) in the temperature range of $50{ }^{\circ} \mathrm{C}$ to $1200^{\circ} \mathrm{C}$ at a heating rate of $10^{\circ} \mathrm{C} / \mathrm{min}$. Perkin Elmer 1650 Infra-Red Spectrometer (USA) was used for FTIR analysis in the range of $4000 \mathrm{~cm}^{-1}$ to $400 \mathrm{~cm}^{-1}$. $\mathrm{N}_{2}$ adsorption-desorption was employed to determine the surface area, average pore diameter, and pore volume at $-196{ }^{\circ} \mathrm{C}$ using Fisher Thermo Scientific SURFER (USA). The morphology and the chemical composition of the samples were obtained using field emission scanning electron microscopy/energy dispersive X-ray analysis (FESEM-EDX) (Supra $^{\mathrm{TM}} 35 \mathrm{VP}$ operating at $10 \mathrm{kV}$ ) (Germany). Additionally, ${ }^{27} \mathrm{Al}$ MAS NMR analysis was used to determine the coordination, phase, and crystallinity of alumina. The spectra were recorded at room temperature on a Bruker Fourier 300 NMR spectrometer with magic angle spinning (MAS) at a frequency of $104.17 \mathrm{MHz}$, using $4 \mathrm{~mm}$ Zirconia rotor spinning in the air at a rate of $10 \mathrm{kHz}, 1.5 \mu \mathrm{s}$ pulse, $2 \mathrm{~s}$ recycle delay and 200 scans. The chemical shifts were referenced to a $1 \% \mathrm{Al}\left(\mathrm{NO}_{3}\right)_{3}$ aqueous solution. Finally, the chemical compositions were established using energy dispersive X-ray fluorescence spectrometer NEX CG (USA).

\subsection{Transesterification reaction}

A specific amount of the catalyst ( 3 to $6 \mathrm{wt} \%$ based on oil) was added to $7 \mathrm{~mL}$ of methanol in a $250 \mathrm{~mL}$ doublenecked round bottom flask fitted with condenser and thermometer and stirred for $20 \mathrm{~min}$ at $65^{\circ} \mathrm{C}$ in a paraffin oil bath. To this mixture, $11 \mathrm{~mL}$ of corn oil (oil: methanol ratio 1:15) was added with continuous stirring for $1 \mathrm{~h}$ at $65^{\circ} \mathrm{C}$. After the completion of the reaction, the products were allowed to settle overnight, then centrifuged at $3000 \mathrm{rpm}$ for $15 \mathrm{~min}$, followed by biodiesel separation. The procedure was repeated for 1:6 and 1:11 molar ratio, as well as 2 and $3 \mathrm{~h}$ reaction time. The biodiesel yield was computed from the ${ }^{1} \mathrm{H}$ NMR spectroscopy result using the relationship in Eq. 7;

Percentage yield $=\frac{2 A_{1}}{3 A_{2}} \times 100$

where; $A_{1}$ is the peak area of the methoxy protons from methyl esters (singlet) at $3.7 \mathrm{ppm}$ and $\mathrm{A}_{2}$ is the peak area of the a-carbonyl methylene groups from fatty ester (triplet) at $2.3 \mathrm{ppm}[9,16]$. The overall transesterification reaction is represented in Eq. 8. 


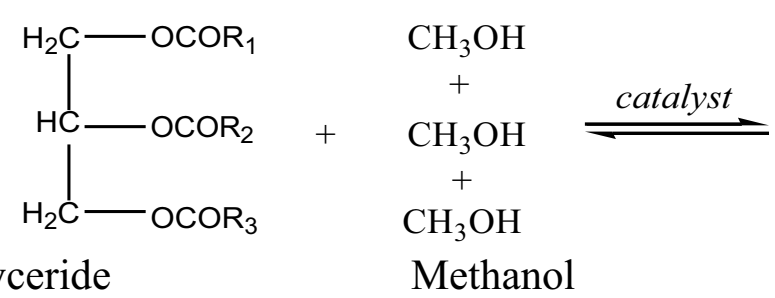

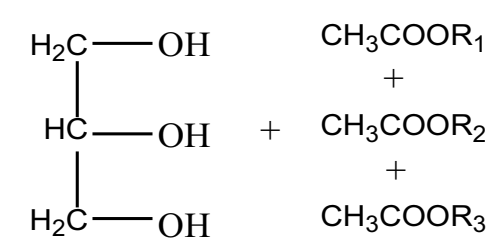

Glycerol Methyl esters

\section{Results and discussion}

\subsection{X-Ray powder diffraction (XRD)}

The wide-angle diffractogram in Fig. 1 revealed characteristic peaks at $2 \theta=32^{\circ} 38^{\circ}, 46^{\circ}$, and $67^{\circ}$ assigned respec-

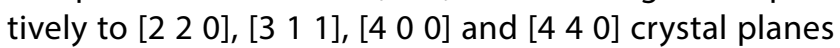
(JCPDS Card no 10-0425) for all the alumina samples. The broad peaks in all the samples signify small crystallites with a small diameter [17]. The similarity in the diffractogram indicates that the alumina phase is not considerably influenced by the PS amount [29]. Nevertheless, a slight improvement in crystallinity with increasing PS concentration is observed. The alumina synthesized using $0.45 \mathrm{~g}$ PS portrayed very broad peaks implying a disordered arrangement of very small crystallite making up the pores [11]. With $0.9 \mathrm{~g} \mathrm{PS}$ addition, the amorphous nature is unchanged, however, there are improved peaks intensities.
Further improvement in the peaks intensity is observed with $1.8 \mathrm{~g}$ PS. Conversely, there is a decline in peak intensity with 3.6 and $4.5 \mathrm{~g}$ PS addition. The low peaks intensity with $0.45 \mathrm{~g}$ PS may result from the non-formation of micelles due to low surfactant concentration. When the surfactant amount is increased to $0.9 \mathrm{~g}$ the concentration may still be below the critical micelles concentration (CMC), but some micelles might have started forming. The CMC was probably attained with $1.8 \mathrm{~g}$ PS addition as a result of an increase in micelles aggregation number, which lead to an orderly arrangement of the crystallites. While the decreased in peaks intensity with 3.6 and $4.5 \mathrm{~g}$ PS addition is likely due to a change in the shape of the micelles [4]. It may also result from the low Al-O-Al connectivity, ensuing from high surfactant content that leads to structure collapsed during calcination [28].

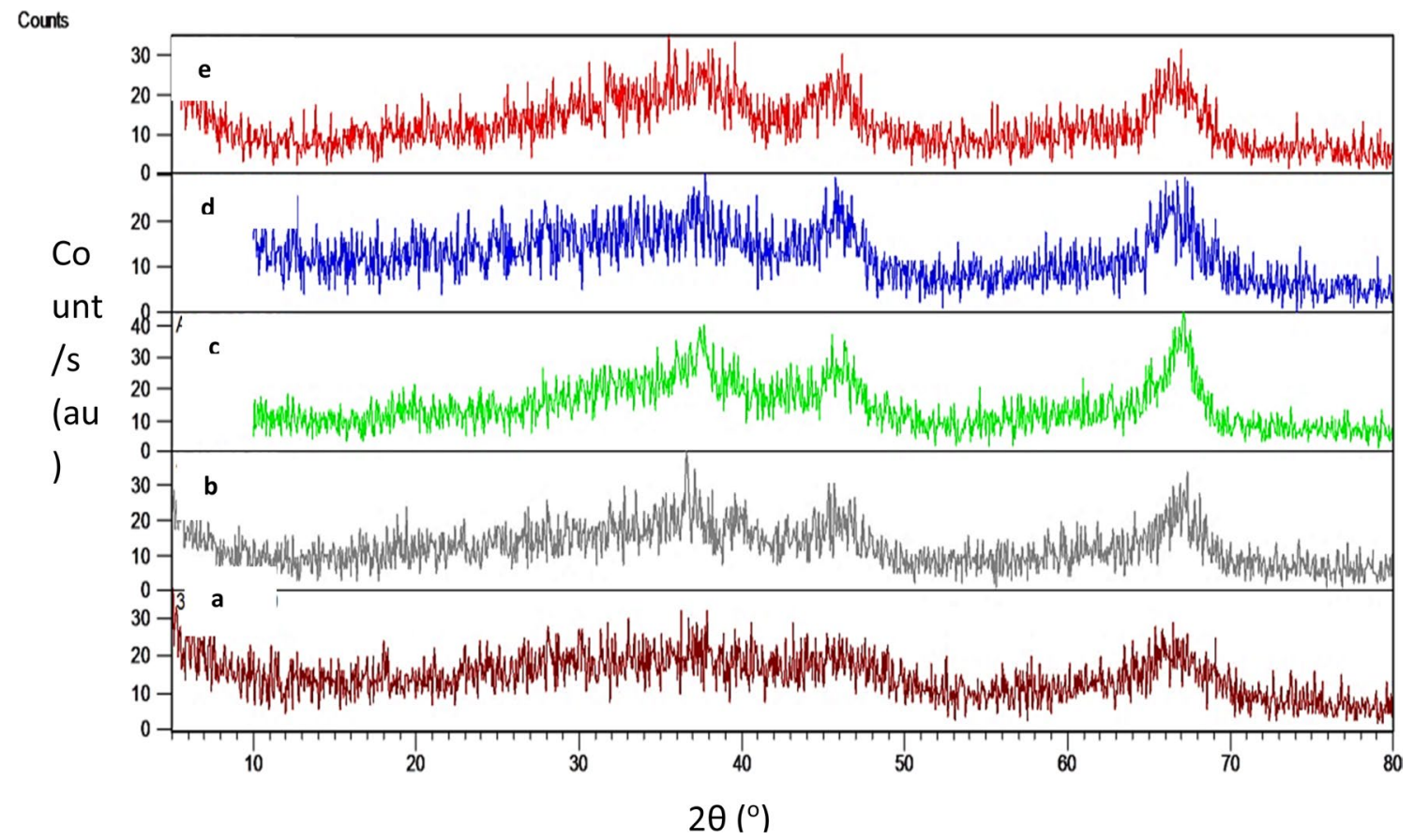

Fig. 1 XRD diffractogram of a Al-0.45-2, b Al-0.9-2, c Al-1.8-2, d Al-3.6-2 and e Al-4.5-2 

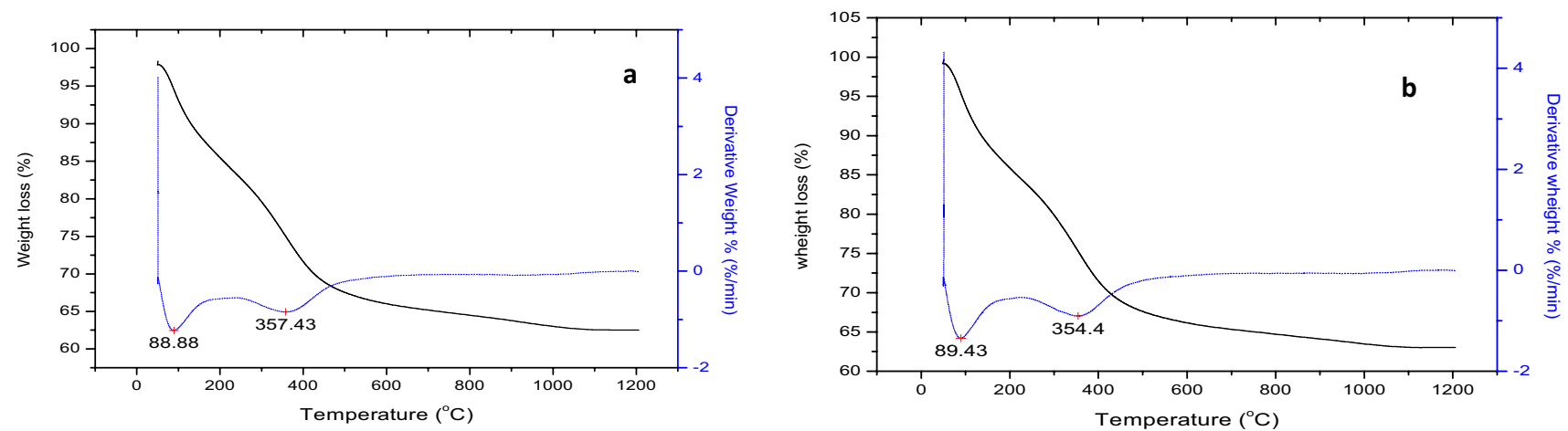

Fig. 2 TG-DTG of a Al-1.8-2 AlOOH precursor and $\mathbf{b}$ AlOOH precursor without PS

\subsection{Thermogravimetric-Derivative thermal gravimetric (TG-DTG)}

Two major weight losses are observed from the TG-DTG curves in Fig. 2. The first weight loss ensued between $50^{\circ} \mathrm{C}$ and $110^{\circ} \mathrm{C}$, which is around $6.3 \%$ and $4.1 \%$ for 2 and 3 days of aging time, respectively. This is attributed to both desorption of physically adsorbed water and removal of the template since the boiling point of $P S$ is around $100^{\circ} \mathrm{C}$. The low boiling point of PS implies that had it been the calcination was carried out in a nitrogen flow, the surfactant could be collected for reuse This signifies the added benefit of using PS in line with environmental friendliness and process economy. The second weight loss between $110^{\circ} \mathrm{C}$ and $600{ }^{\circ} \mathrm{C}$ is about $12.4 \%$ and $7.1 \%$ respectively for 2 and 3 days of aging, which is attributed to the release of chemically adsorbed water molecules and dehydroxylation of boehmite precursor. The larger weight loss observed in the first region of the TG-DTG curve for 2 days of aging compared to 3 days may be due to the adsorption of more surfactant onto the precursor with 2 days aging time and the subsequent reversal of the adsorption process with increasing aging time. The adsorption of surfactant is associated with the surfactant micelles affinity to the surfaces of boehmite crystallites $[3,47]$. Whereas the same observation in the second region of chemically adsorbed water may be attributed to the higher replacement of chemisorbed water in the alumina framework by the surfactant with 2 days of aging compared to 3 days.

Interestingly, for the precursor synthesized without surfactant, two mass losses respectively for physically and chemically adsorbed water of around $11.8 \%$ and $18.0 \%$ were also obtained. The lower mass losses in the alumina synthesized with PS addition compared to that without

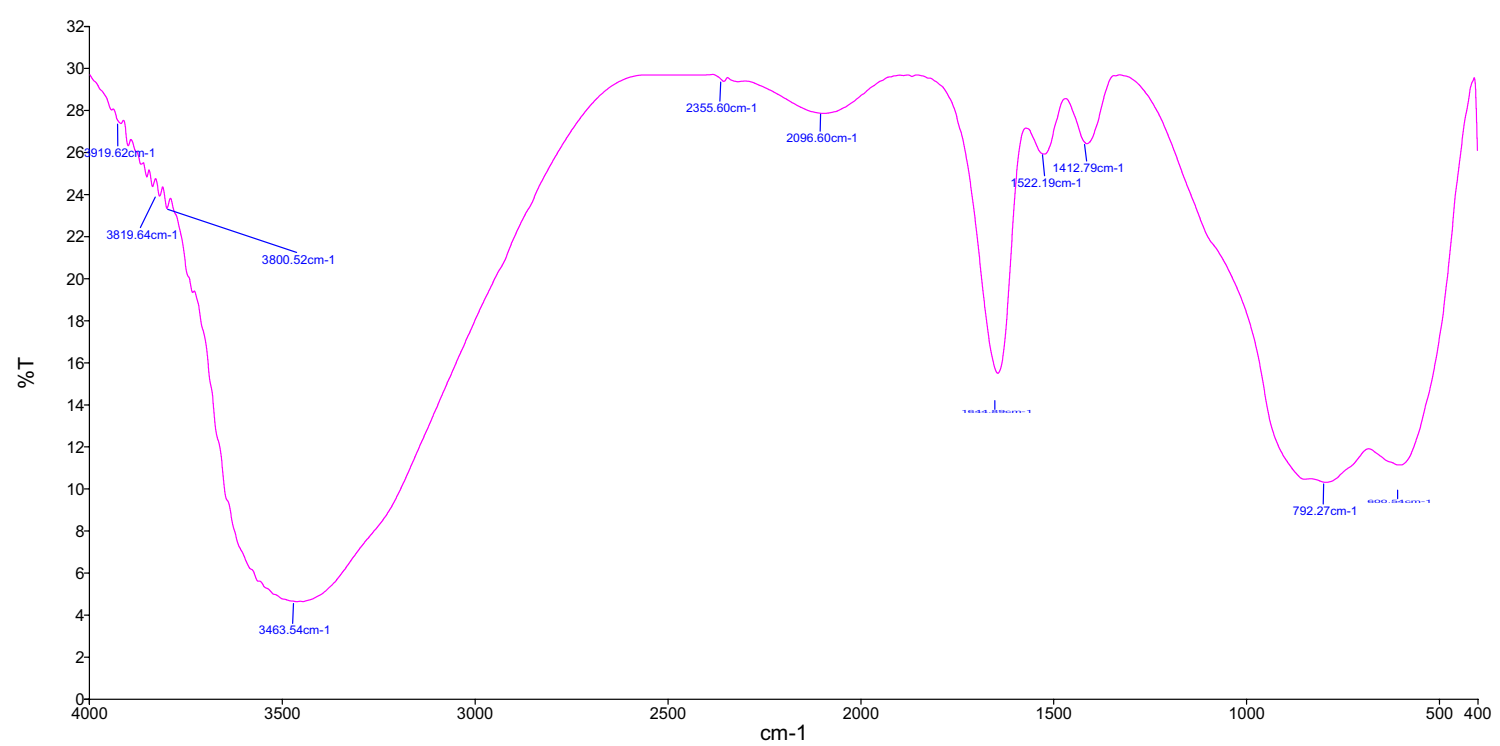

Fig. 3 Error! No text of specified style in document.: FTIR spectrum of Al-1.8-2 

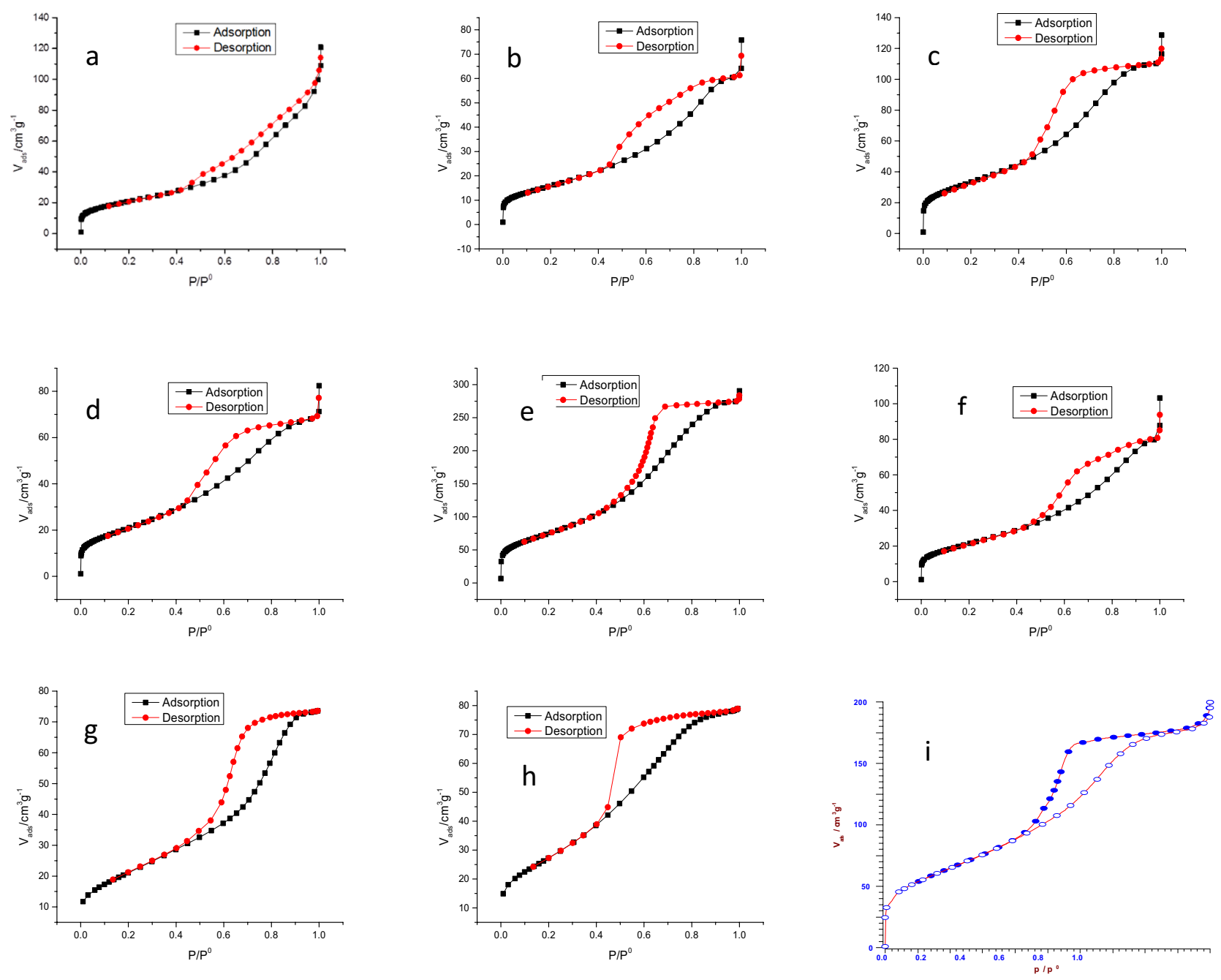

Fig. $4 \mathrm{~N}_{2}$-sorption isotherm of a Al-0.45-2, b Al-0.45-3, c Al-0.9-2, d Al-0.9-3, e Al-1.8-2, f Al-1.8-3, g Al-3.6-2, h Al-4.5-2 and i) Al-500

surfactant emphasized the interaction of the surfactant with the boehmite precursor. The surfactant probably interacted and changed the structure of the precursor by breaking the hydrogen bonding thereby replacing the water molecules in the precursor.

\subsection{Fourier transform infra-red spectroscopy (FTIR)}

The spectrum for alumina synthesized with $1.8 \mathrm{~g}$ PS and aged for 2 days is depicted in Fig. 3, displaying peaks around $3463,2096,1642,1401,767,579 \mathrm{~cm}^{-1}$. Peaks at 3455 and $1642 \mathrm{~cm}^{-1}$ are attributed respectively to the stretching and bending vibration of $\mathrm{OH}$. While peak around $1401 \mathrm{~cm}^{-1}$ confirmed the formation of alumina [31, 32 , 44]. Lastly, bands at 767 and $579 \mathrm{~cm}^{-1}$ are assigned to $\mathrm{AlO}_{4}$ and $\mathrm{AlO}_{6}$, respectively.

\subsection{Nitrogen adsorption-desorption analysis}

From the $\mathrm{N}_{2}$-sorption isotherms in Fig. 4, all samples exhibited type IV isotherm characteristic of mesoporous materials. The hysteresis loops for Al-0.45-2 and Al-0.45-3 are $\mathrm{H} 4$, implying a slit-shaped pore [34]. But, the hysteresis loop of Al-0.45-3 is wider, demonstrating a uniform slitshaped pore [46]. In the case of Al-0.9-2 and Al-0.9-3, a mixture of $\mathrm{H} 2$ and $\mathrm{H} 4$ hysteresis loop is observed, indicating the transformation from $\mathrm{H} 4$ to $\mathrm{H} 2$ with increasing surfactant concentration. Whereas, the Al-1.8-2 portrayed $\mathrm{H} 2$ hysteresis loop, further substantiating $\mathrm{H} 4$ to $\mathrm{H} 2$ transformation with increasing surfactant concentration. The $\mathrm{H} 2$ hysteresis loop implies a narrow entrance pore $[5,46]$. This narrow pore is associated with the complex nature of the $\mathrm{H} 2$ hysteresis loop as it is formed from interconnected networks of the pore, either ink-bottle or channel-like pores, of different sizes and shapes [34, 37]. With regards 
to $\mathrm{Al}-1.8-3$, a mixture of $\mathrm{H} 4$ and $\mathrm{H} 2$ is observed, probably due to the transformation of $\mathrm{H} 2$ back to $\mathrm{H} 4$ as a result of the attainment of equilibrium after 2 days and subsequent reversal with 3 days of aging. Finally, the hysteresis loops for Al-3.6-2 and Al-4.5-2 are $\mathrm{H} 2$.

Additionally. the isotherms for all the samples synthesized with PS revealed a narrow pore size distribution characteristic of ordered materials [21]. The narrow hysteresis loop implies the regularity of mesoporous alumina [41]. Moreover, the steepness of the adsorption branch of the isotherms indicated an improved uniformity of mesopores [45]. This is attributed to good interaction between the surfactant and boehmite precursor. On the other hand, the sample synthesized without surfactant addition also portrayed type IV isotherm with an $\mathrm{H} 2$ hysteresis loop indicating the existence of mesoporous materials. This can be attributed to inter particles pores formed by the close stacking of primary and secondary particles, that cannot be controlled since it only depends on the shape, the uniformity, and the arrangement of the primary and secondary particles in the precursor [21,23]. Although mesoporous alumina is obtained even without PS addition, microporosity is detectable from the low-pressure part of its isotherm, indicating non-uniform mesoporous alumina.

The textural parameters of various alumina are presented in Table 1. The surface area is observed to increased with an increasing amount of surfactant from 0.45 to $1.8 \mathrm{~g}$, then decreased with 3.6 and $4.5 \mathrm{~g}$ PS addition. The low surface area with $0.45 \mathrm{~g}$ PS may be due to the surfactant concentration been lower than the critical micelles concentration (CMC). The micelles likely began to formed with $0.9 \mathrm{~g}$ PS addition, however, with few aggregation numbers.

Table 1 Summary of textural properties of alumina from $\mathrm{N}_{2}$ adsorption-desorption analysis

\begin{tabular}{lccc}
\hline Sample & $\begin{array}{l}\text { Surface area } \\
\left(\mathrm{m}^{2} / \mathrm{g}\right)\end{array}$ & $\begin{array}{l}\text { Average pore diam- } \\
\text { eter }(\mathrm{nm})\end{array}$ & $\begin{array}{l}\text { Pore } \\
\text { volume } \\
\left(\mathrm{cm}^{3} / \mathrm{g}\right)\end{array}$ \\
\hline Al-0.45-1 & 47.3 & - & - \\
Al-0.45-2 & 76.0 & 4.4 & 0.14 \\
Al-0.45-3 & 59.1 & 2.5 & 0.09 \\
Al-0.9-1 & 63.5 & - & - \\
Al-0.9-2 & 122.3 & 2.3 & 0.17 \\
Al-0.9-3 & 78.4 & 2.3 & 0.11 \\
Al-1.8-1 & 191.8 & - & - \\
Al-1.8-2 & 319.2 & 2.7 & 0.42 \\
Al-1.8-3 & 79.5 & 2.8 & 0.12 \\
Al-3.6-2 & 76.7 & 5.7 & 0.11 \\
Al-4.5-2 & 102.4 & 4.3 & 0.12 \\
${ }^{*}$ Al-500 & 169.0 & 4.4 & 0.32 \\
\hline
\end{tabular}

a alumina synthesized without surfactant
The highest surface area with $1.8 \mathrm{~g}$ PS addition may be owing to the enrichment of micelles aggregation numbers and attainment of CMC. Conversely, the decline in surface area with 3.6 and $4.5 \mathrm{~g}$ PS addition may be ascribed to high surfactant content that resulted in the collapse of the structure during calcination due to low $\mathrm{Al}-\mathrm{O}-\mathrm{Al}$ connectivity. The structure collapsed may also be ascribed to temperature overshoot caused by the highly exothermic nature of surfactant combustion [28]. Another possible reason for the low surface area is a change in the shape of the micelles with increasing micelles size due to high surfactant concentration. Consequently, the micelles become crowded generating repulsive forces due to limitation on the conformation of oxyethylene groups arising from steric hindrance, this leads to a micelles shape transition, for instance from sphere to a rod that favour a higher degree of structuration [4].

Furthermore, the surface area increased with aging time from 1 to 2 days then decreased with 3 days aging, for all surfactant concentrations. This may lend itself to the fact that the individual surfactant molecules are in equilibrium with the micelles, with increasing aging time the formation of micelles is favoured and probably reached equilibrium in 2 days, and when the aging time reached 3 days, the micelles probably reversed back to the individual molecules and caused a decreased in the surface area. On the other hand, the surface area of the alumina synthesized without PS addition is found to be $169.0 \mathrm{~m}^{2} / \mathrm{g}$. This indicated that although mesoporous alumina is formed even without surfactant, its addition in the right concentration and aging time resulted in mesoporous alumina with a larger surface area.

Besides, the average pore diameter also increased with PS amount from 0.9 to $4.5 \mathrm{~g}$, perhaps due to the increase in the aggregation number of micelles with increasing surfactant concentration. For that, the unexpected large average pore diameter observed for Al-0.45-2 may be due to concentration been lower than $\mathrm{CMC}$, as such the pore diameter assumed the size of the surfactant individual molecules. Conversely, the low average pore diameter of alumina synthesized with 0.9 and $1.8 \mathrm{~g}$ PS indicated the surfactant is existing in micellar form, hence the pore diameter presumed the size of the micelles, not the individuals' molecules. While the large average pore diameter for Al-3.6-2 and Al-4.5-2 may be attributed to the micelles shape transition. Moreover, the unfavourable effect of pore volume shrinkage with PS addition above $1.8 \mathrm{~g}$ may be owing to the uneven distribution of the large excess surfactant, leading to shrinkage of the pore structure during calcination [3]. In comparison, the average pore diameter and pore volume for the alumina without PS addition is $4.4 \mathrm{~nm}$ and $0.32 \mathrm{~cm}^{3} / \mathrm{g}$, respectively. This pore volume is similar to that obtained with $\mathrm{Al}-0.45-2$ which affirmed the 


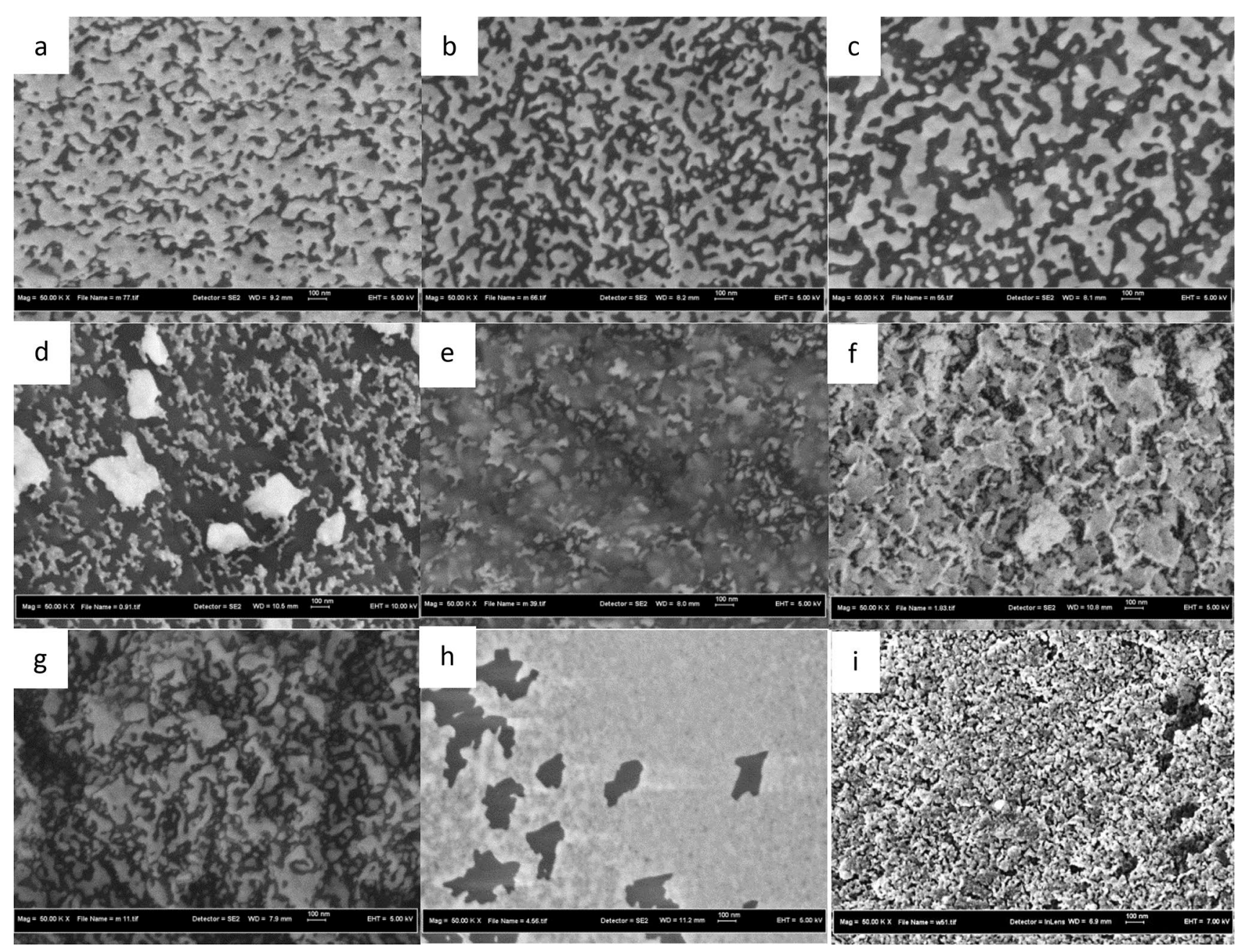

Fig. 5 FESEM images of a Al-0.45-1, b Al-0.45-2, c Al-0.9-1, d Al-0.9-2, e Al-1.8-1, f Al-1.8-2, g Al-3.6-2, h Al-4.5-2 and h Al-500

assertion that the average pore diameter relies on the size of the surfactant micelles.

Besides, the t-plot, not presented here, gives more insight into the pore structure. When the low-pressure part of the t-plot is back extrapolated it passed through the origin for almost all the alumina samples synthesized with the surfactant, indicating the absence of detectable micropores. This can be confirmed by the good agreement between the total surface area calculated from the slope of the linear part with the BET surface area from $\mathrm{N}_{2}$ adsorption [11]. The absence of micro-porosity coupled with a narrow hysteresis loop signified the regularity of the synthesized mesoporous alumina. On the contrary, for the alumina synthesized without surfactant, the t-plot did not pass through the origin, affirming the presence of microporosity.

\subsection{Field emission scanning electron microscopy (FESEM)}

The FESEM images of the alumina samples are portrayed in Fig. 5. For alumina synthesized with 0.45 and $0.9 \mathrm{~g} \mathrm{PS}$, a wormhole like morphology is obtained. The morphology became more uniform with aging time from 1 to 2 days then dropped with 3 days aging. While the Al-1.8-1 alumina sample showed agglomerated particles, which opened up to a flaky-like morphology with 2 days of aging time (Al-1.8-2). Further increasing the aging time to 3 days, the morphology changed to a worm-like structure for the Al-1.8-3 sample. Highly agglomerated worm-like morphologies are observed for Al-3.6-2 and Al-4.5-2 samples. Similarly, the morphology of alumina synthesized without PS (Al-500) is wormhole-like, however with less agglomerated particles that appeared larger than those with the surfactant, indicating improved regularity with surfactant addition. 
The detected changes in the morphology with PS concentration further affirmed the effect of surfactant on the alumina structural properties as established by XRD and $\mathrm{N}_{2}$ sorption analyses. Additionally, the observed improvement in the uniformity of the alumina morphology with increasing aging time may be due to the enhancement in micelles stability with aging time. This concurred with the isotherm result, where the hysteresis loop kept changing with surfactant amount and aging time. The 2 days aging has been the best for all surfactant concentrations, probably due to the attainment of equilibrium at 2 days. The improvement in the morphology with surfactant addition is perhaps due to the combined effects of hydrogen bonding and coordination bonding. Whereas the weak coordination bonding leads to the formation of a crownether-type complex between the alkylene oxide segment of PS and $\mathrm{Al}^{3+}$ ions in the boehmite. While the hydrogenbonding bridged the hydrophilic polyethylene oxide (PEO) head group of the surfactant with the $\mathrm{OH}$ groups on the surface of the boehmite layers [24]. For these reasons, the surfactant caused a partial breakage of the hydrogenbonding holding the boehmite layers together and successfully formed a new bond with the $\mathrm{AlOOH}$ precursor.

\section{$3.6{ }^{27}$ AI MAS NMR}

From the ${ }^{27} \mathrm{Al}$ MAS NMR spectrum of Al-1.8-2 in Fig. 6, two resonance signals are detected around 7 and $70 \mathrm{ppm}$ assigned respectively to octahedral $\left(\mathrm{AlO}_{6}\right)$ and tetrahedral $\left(\mathrm{AlO}_{4}\right)$ coordination. This is in consent with the FTIR result that also revealed peaks due to $\mathrm{AlO}_{6}$ and $\mathrm{AlO}_{4}$. The presence of $\mathrm{AlO}_{6}$ and $\mathrm{AlO}_{4}$ coordinated alumina species implies a crystalline alumina phase $[10,26,38]$. The ratio of six- to four-coordinated $\mathrm{Al}$ ( $\mathrm{Al}^{\mathrm{vi}} / \mathrm{Al}^{\mathrm{iv}}$ ) in the range of 1.6-2.3 signifies the presence $\eta$-alumina, while $2.4-3.8$ suggests $\gamma$-alumina. The value of 4.8 obtained in this study implies a more active $\gamma$-alumina phase due to high $\mathrm{Al}^{\mathrm{vi}}$ content compared to completely dehydrated alumina [20].

\subsection{X-ray fluorescence (XRF)}

To ascertained the degree of purity of the alumina, XRF analysis was performed before and after the calcination of the precursor. The $\mathrm{Al}_{2} \mathrm{O}_{3}$ composition was found to be $90.8 \%$ in the $\mathrm{AlOOH}$ precursor, whereas it is up to $98 \%$ in the alumina sample after calcination. This indicated the high purity of the synthesized mesoporous alumina in this study, demonstrating the benefit of introducing the step for the precipitation of impurity in the synthesis procedure. This assertion is true when this result is compared to that by Salahuddeen et al. (2015) where $83.47 \mathrm{wt} . \%$ of aluminium oxide was detected in the alumina synthesized from kaolin.

\subsection{Proposed mechanism of formation}

From the results of the alumina characterization, it is established that PS being a non-ionic surfactant has a small impact on the boehmite precursor due to weak interaction between the two. Despite this weak interaction, the PS induced a small change in the morphology and structural properties of the boehmite layers, as apparent from

Fig. 6 NMR spectra of Al-1.8-2

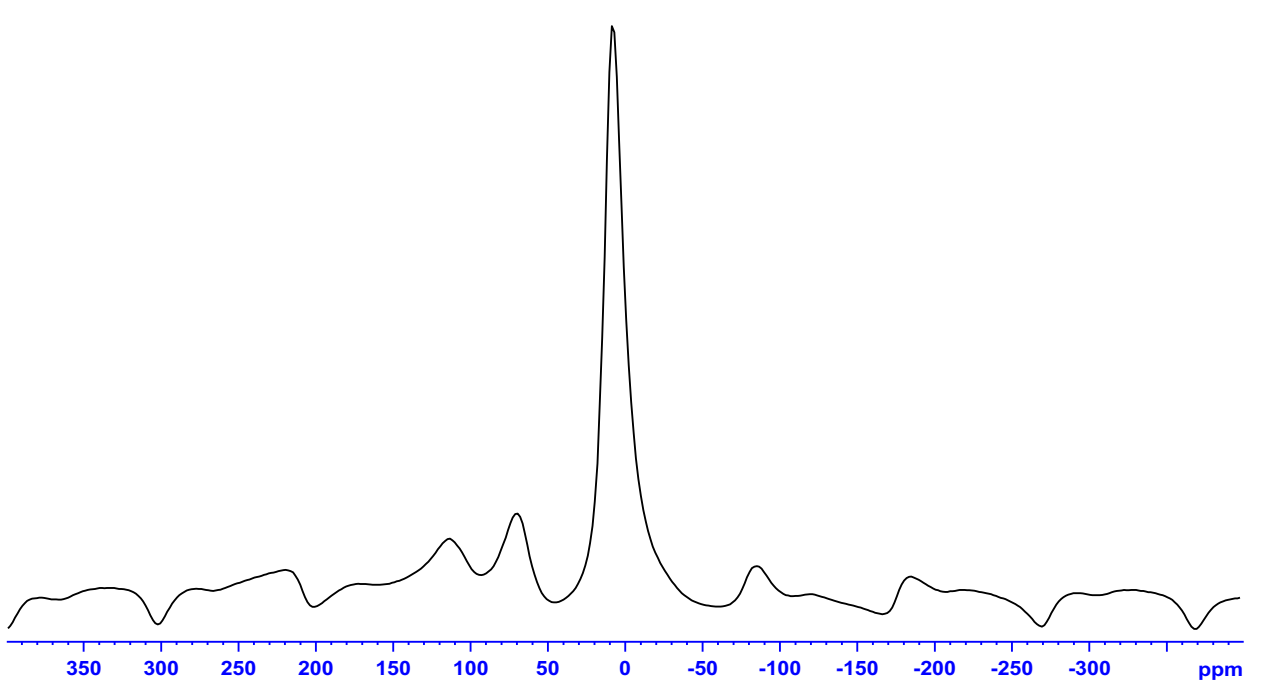


the XRD, $\mathrm{N}_{2}$ sorption, and FESEM results. The addition of PS helped in the formation of much smaller particles, attributable to the obstruction of hydrolysis and condensation of the precursor by adsorption of PS at the particle surface through hydrogen-bonding between $\mathrm{Al}^{3+}$ Lewis acidic site and the basic oxygen of the ethoxy group of PS or by electrostatic interaction. Thus, the PS enveloped and linked the inorganic $\mathrm{Al}^{3+}$ ions through bridging bond connections, thereby slowing down the hydrolysis of aluminium, which would otherwise be very fast and resulted in the formation of large and thick lamellar hydrated hydroxides. Furthermore, the PS acts as a structure-directing reagent and prevented single-particle aggregation, favouring the formation of mesostructured $\mathrm{AlOOH}$ precursor with more uniform particles [39]. Since the kaolin as a raw material has a very small particle size $(<2 \mu \mathrm{m})$, the $\mathrm{AlOOH}$ without PS could possed micro-structure due to single particle aggregation, which would have undergone rearrangement through condensation reaction during the drying process to form pores with similar sizes as can be seen from the detectable microporosity in the alumina synthesized without surfactant [18]. This is substantiated by the fact that the factor controlling the final porosity is the nature of the alumina source [41]. The schematic illustration of the role of PS in the mesoporous gamma-alumina synthesis is depicted in Fig. 7. In the first stage; (I) the PS interacts with the boehmite particles, followed by, (II) PS connection of the $\mathrm{Al}^{3+}$ ions in the boehmite, and lastly (III) the formation of flaky-like morphology after removing PS by calcination.

\section{Catalyst characterization}

\subsection{Fourier transform infra-red (FTIR) of the catalyst}

From the FTIR spectrum of the $15-\mathrm{Na} / \mathrm{Al}-1.8-2$ catalyst in Fig. 8 , it is apparent that all peaks of the as-synthesized alumina are retained. Nevertheless, the catalyst spectrum revealed a new peak around $1394 \mathrm{~cm}^{-1}$, associated with
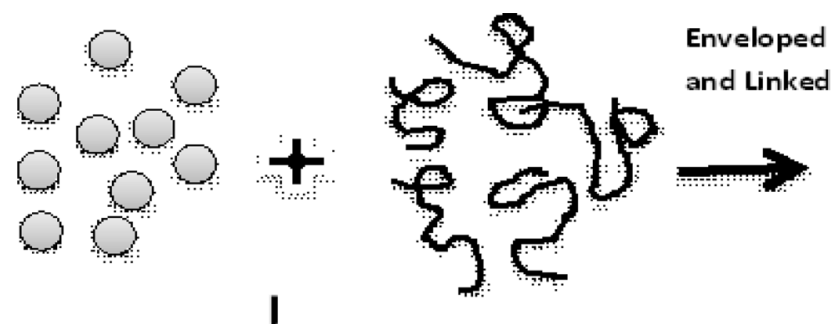

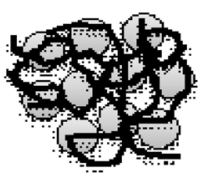

II

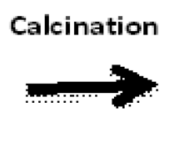

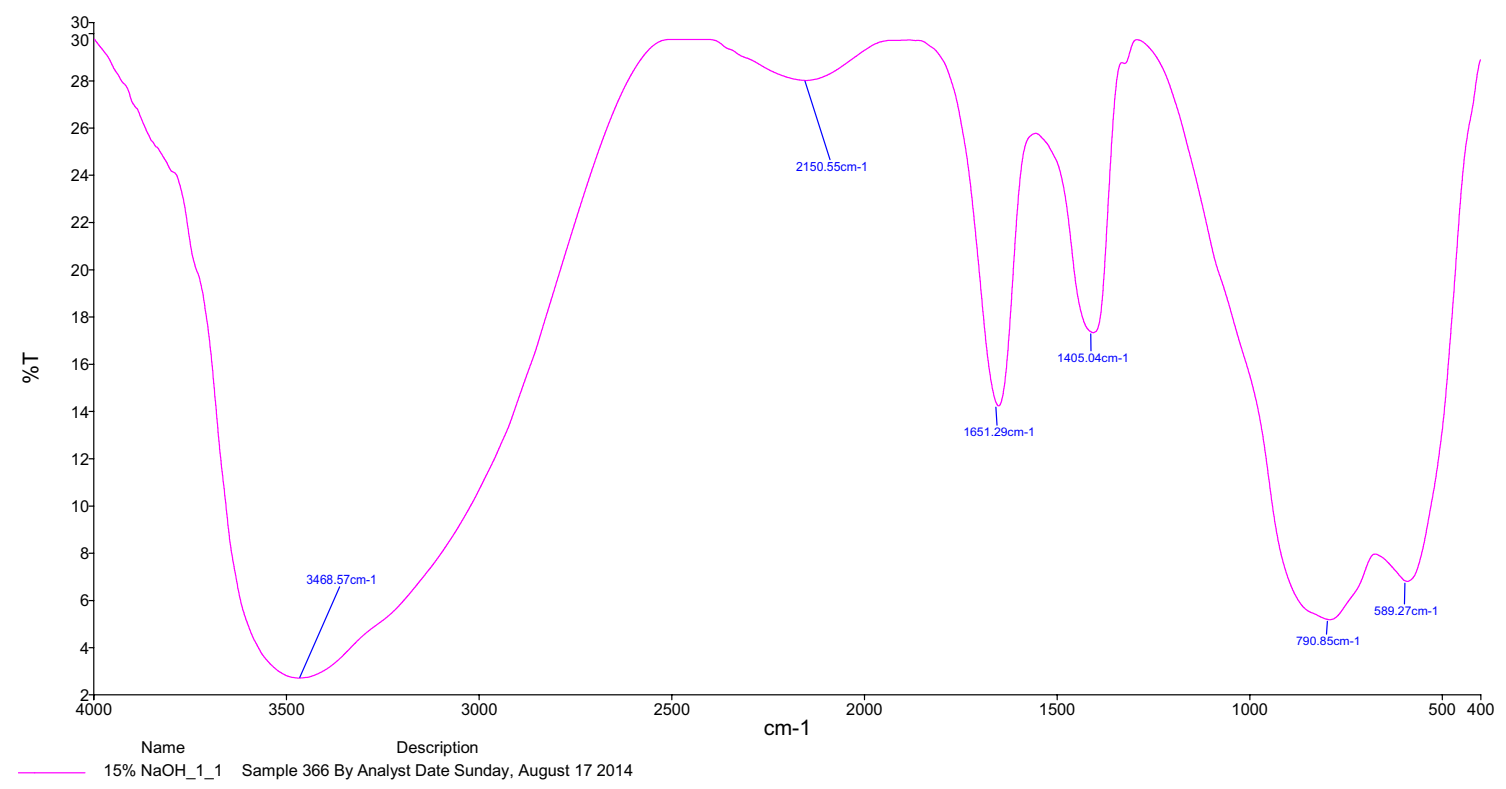

Fig. 8 Error! No text of specified style in document.: FTIR spectrum of 15-Na/Al-1.8-2 

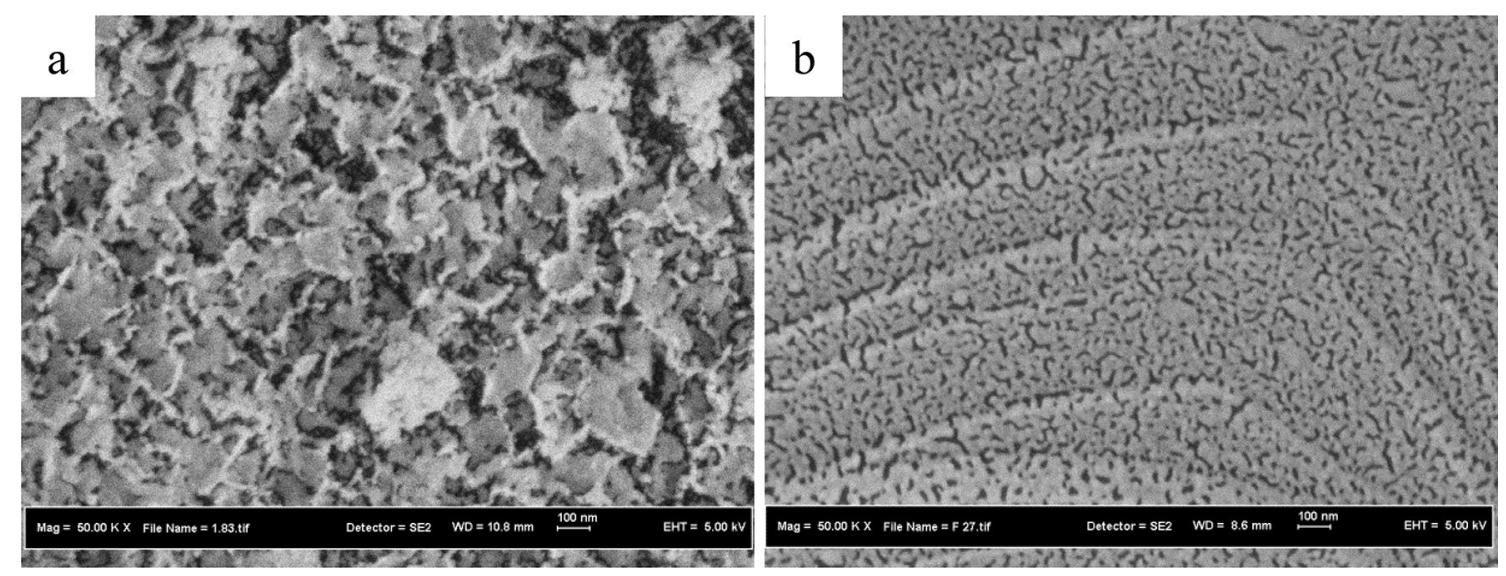

Fig. 9 FESEM image of a Al-1.8-2 and b 15-Na/Al-1.8-2

Table 2 Percentage yields of biodiesel

\begin{tabular}{llll}
\hline $\begin{array}{l}\text { Catalyst loading } \\
\text { (wt\%) }\end{array}$ & $\begin{array}{l}\text { Oil: methanol } \\
\text { (molar) }\end{array}$ & Rxn. Time (h) & Yield (\%) \\
\hline 3 & $1: 6$ & 2 & 45.11 \\
3 & $1: 11$ & 1 & 76.05 \\
3 & $1: 11$ & 3 & 89.72 \\
3 & $1: 15$ & 2 & 90.46 \\
4.5 & $1: 6$ & 1 & 40.32 \\
4.5 & $1: 6$ & 3 & 54.08 \\
4.5 & $1: 11$ & 2 & 92.72 \\
4.5 & $1: 15$ & 1 & 86.72 \\
4.5 & $1: 15$ & 3 & 96.88 \\
6 & $1: 6$ & 2 & 55.31 \\
6 & $1: 11$ & 1 & 87.50 \\
6 & $1: 11$ & 3 & 97.72 \\
6 & $1: 15$ & 2 & 99.46 \\
\hline
\end{tabular}

anti-symmetric vibration of carbonate, signifying basic site generation $[22,25,42]$. This surface carbonate is formed as a result of chemisorption of $\mathrm{CO}_{2}$ molecule, an acidic gas, by oxide anion, a phenomenon for assessing basic sites of compounds.

\subsection{BET surface area of the catalyst}

The surface area of the Al-1.8-2 alumina decreased from 319.2 to $191.2 \mathrm{~m}^{2} / \mathrm{g}$ in the $15-\mathrm{Na} / \mathrm{Al}-1.8-2$ catalyst. The observed decreased in the surface area with modification can be ascribed to the coverage of the mesoporous channels by the $\mathrm{NaOH}$ species [33].
Table 3 Comparison of biodiesel yield of different modified alumina catalysts

\begin{tabular}{|c|c|c|}
\hline Catalyst & $\%$ Yield & Reference \\
\hline $15-\mathrm{Na} / \mathrm{Al}-1.8-2$ & 99.46 & This study \\
\hline $\mathrm{Na} / \mathrm{NaOH} / \mathrm{\gamma}-\mathrm{Al}_{2} \mathrm{O}_{3}$ & 83 & [19] \\
\hline $\mathrm{NaOH} / \mathrm{Al}_{2} \mathrm{O}_{3}$ & 86 & [1] \\
\hline $\mathrm{NaOH} / \mathrm{Al}_{2} \mathrm{O}_{3}$ & 99 & [40] \\
\hline $\mathrm{KI} / \mathrm{Al}_{2} \mathrm{O}_{3}$ & 96 & {$[43]$} \\
\hline $\mathrm{KF} / \mathrm{Al}_{2} \mathrm{O}_{3}$ & 99.6 & [6] \\
\hline $\mathrm{CaO} / \mathrm{KI} / \mathrm{Al}_{2} \mathrm{O}_{3}$ & 95 & [2] \\
\hline $\mathrm{KI} / \mathrm{Al}_{2} \mathrm{O}_{3}$ & 95.2 & [8] \\
\hline $\mathrm{KF} \& \mathrm{NaNO}_{3} / \mathrm{Al}_{2} \mathrm{O}_{3}$ & $80 \& 87 \%$ & [12] \\
\hline
\end{tabular}

\subsection{FESEM analysis of the Catalyst}

The FESEM images of Al-1.8-2 and 15-Na/Al-1.8-2 are compared in Fig. 9. It is clear the flaky like morphology of the Al-1.8-2 alumina changed into a wormlike structure for $15-\mathrm{Na} / \mathrm{Al}-1.8-2$ catalyst and the particles agglomerated. The agglomeration of the particles may be another reason for the surface area lowering with modification. It also indicated the integration of $\mathrm{Na}$ into the alumina support.

\subsection{Biodiesel analysis}

The biodiesel yields at various reaction conditions are displayed in Table 2 . The yield is observed to be vastly influenced by the oil: methanol molar ratio, followed by reaction time, while catalyst loading is with the least effect. This is in line with the fact that the oil to methanol molar ratio is the most important parameter that affects not only biodiesel yield but also production cost. The high biodiesel yield with increasing oil to methanol ratio is associated with the equilibrium nature of the methanolysis reaction, 
in which the excess alcohol drives the reaction to the product side. Besides, the use of excess alcohol simplifies biodiesel separation from the catalyst surface for the regeneration of the active sites, thus reducing the production cost [15]. The effect of reaction time can be justified by the fact that the equilibrium is approached with time. With increasing reaction time the biodiesel yield increased until optimum yield is obtained at equilibrium time. Finally, the catalyst loading having the least influence on the biodiesel yield affirmed the high basic sites of the catalyst, as such high biodiesel yield is obtained even with low catalyst loading provided other parameters are set to optimum.

To ascertained the influence of the structural properties on the catalytic activity of the mesoporous alumina, the yield obtained by the modified mesoporous gammaalumina in this study is compared with those of the modified commercial gamma-aluminas in the literature and presented in Table 3. Although some of these works used up to $50 \%$ dopant yet the percentage yield is still lower or similar to what we obtained in this study. This is even though only $15 \%$ of $\mathrm{NaOH}$ is used as a dopant in this work. The high biodiesel yield in the present study will not be unconnected to the improved structural properties and morphology of the mesoporous gamma-alumina.

\section{Conclusion}

Mesoporous $\gamma$-alumina with relatively large surface area, narrow average pore diameter, and pore volume was successfully synthesized from kaolin in the presence of PS by varying the surfactant concentration and aging time. The textural properties of the mesoporous alumina improved with increasing surfactant amount from $0.45 \mathrm{~g}$ to $1.8 \mathrm{~g}$ and then dropped beyond that. Furthermore, the alumina properties also improved with increasing aging time from 1 to 2 days and decreased with 3 days aging. Thus, Alumina synthesized with $1.8 \mathrm{~g}$ PS addition and aged for 2 days (Al-1.8-2) has the highest surface area of 319.2 $\mathrm{m}^{2} / \mathrm{g}$, a pore volume of $0.42 \mathrm{~cm}^{3} / \mathrm{g}$, and a narrow average pore diameter of $2.7 \mathrm{~nm}$. Additionally, the study proposed that PS addition leads to the formation of much smaller particles, by acting as a structure-directing reagent and prevented single-particle aggregation, thereby forming mesostructured $\mathrm{AlOOH}$ precursor with uniform structure. On modification using $\mathrm{NaOH}$, the basic sites of the synthesized alumina increased, the surface area decreased, while the morphology changed from flaky to a worm-like structure, demonstrating $\mathrm{Na}$ incorporation into the alumina. When the catalyst was applied in the methanolysis of refined corn oil, it was observed to possess very high catalytic activity with a biodiesel yield of up to $99.46 \%$.

Acknowledgement The authors would like to acknowledge the Research Management Centre (RMC), UTM for financial support. We will also like to acknowledge Mrs. Ambiga A/P Gopal of Surface Analysis Lab., UPMU, UTM for her assistance in the analyses of samples.

\section{Compliance with ethical standards}

Conflict of interest I declare that there is no conflict of interest in this manuscript.

Open Access This article is licensed under a Creative Commons Attribution 4.0 International License, which permits use, sharing, adaptation, distribution and reproduction in any medium or format, as long as you give appropriate credit to the original author(s) and the source, provide a link to the Creative Commons licence, and indicate if changes were made. The images or other third party material in this article are included in the article's Creative Commons licence, unless indicated otherwise in a credit line to the material. If material is not included in the article's Creative Commons licence and your intended use is not permitted by statutory regulation or exceeds the permitted use, you will need to obtain permission directly from the copyright holder. To view a copy of this licence, visit http://creativecommons .org/licenses/by/4.0\%.

\section{References}

1. Arzamendi G, Campo I, Argui E (2007) Synthesis of biodiesel with heterogeneous $\mathrm{NaOH}$ /alumina catalysts : comparison with homogeneous $\mathrm{NaOH}$. Chem Eng J 134:123-130

2. Asri, N.P., Savitri, S.D., and Budikarjono, K. (2012) Development of Heterogeneous Alumina Supported Base Catalyst for Biodiesel Production. In: 2012 3rd International Conference on Biology, Environment, and Chemistry, pp. 116-121

3. Bleta R, Alphonse P, Pin L, Gressier M, Menu M (2012) An efficient route to aqueous phase synthesis of nanocrystalline $\mathrm{\gamma}-\mathrm{Al}_{2} \mathrm{O}_{3}$ with high porosity : From stable boehmite colloids to large pore mesoporous alumina. J Coll Interface Sci 367(1):120-128. https ://doi.org/10.1016/j.jcis.2011.08.087

4. Blin JL, Carteret C, Bleta R, Stébé MJ (2010) Preparation and characterization of mesoporous materials from a nonionic fluorinated surfactant : Adsorption of glucose oxidase. Colloids Surf, A 357:128-135. https://doi.org/10.1016/j.colsurfa.2009.10.011

5. Bo M, Xue T, Qian W, Meng Y, He M (2011) CTAB-directed synthesis of mesoporous $\gamma$-alumina promoted by hydroxy carboxylate : The interplay of tartrate and CTAB. Solid-State Sciences 13(2):409-416. https://doi.org/10.1016/j.solidstatescien ces.2010.12.003

6. Boz N, Kara M, Sunal O, Değirmenbaşi N (2009) Investigation of the fuel properties of biodiesel produced over an aluminabased solid catalyst. Turk J Chem 33:433-442

7. Du C, Yang H (2012) Investigation of the physicochemical aspects from natural kaolin to Al-MCM-41 mesoporous materials. J Coll Interface Sci 369(1):216-222. https://doi.org/10.1016/j. jcis.2011.12.041

8. Evangelista JPC, Chellappa T, Coriolano ACF, Fernandes VJ, Souza LD, Araujo AS (2012) Synthesis of alumina impregnated with 
potassium iodide catalyst for biodiesel production from rice bran oil. Fuel Process Technol 104:90-95

9. Gelbard G, Br O, Vargas RM, Vielfaure F, Schuchardt UE (1995) ${ }^{1} \mathrm{H}$ Nuclear magnetic resonance determination of the yield of the transesterification of rapeseed oil with methanol. J Am Oil Chem Soc 72(10):1239-1241

10. Hartmann S, Sachse A, Galarneau A, Charles I, Montpellier G, Cnrs UMR, Enscm UM (2012) Challenges and strategies in the synthesis of mesoporous alumina powders and hierarchical alumina monoliths. Materials 5:336-349. https://doi.org/10.3390/ ma5020336

11. Huang B, Bartholomew CH, Woodfield BF (2013) Facile structure-controlled synthesis of mesoporous $\gamma$-alumina : effects of alcohol in precursor formation and calcination. Microporous Mesoporous Mater 177:37-46. https://doi.org/10.1016/j.micro meso.2013.04.013

12. Islam A, Hui Y, Chu C, Ravindra P, Chan E (2013) Transesterification of palm oil using $\mathrm{KF}$ and $\mathrm{NaNO}_{3}$ catalysts supported on spherical millimetric $\mathrm{\gamma}^{-} \mathrm{Al}_{2} \mathrm{O}_{3}$. Renew Sustain Energy Rev 59:23-29

13. Jiang $X$, Oveisi $H$, Nemoto $Y$, Suzuki N, Wu KC-W, Yamauchi $Y$ (2011) Synthesis of highly ordered mesoporous alumina thin films and their framework crystallization to the $\gamma$-alumina phase. Dalton Trans 40(41):10851-10856. https://doi.org/10.1039/ c1dt10166h

14. Jiao WQ, Yue MB, Wang YM, He M (2012) Synthesis of morphology-controlled mesoporous transition aluminas derived from the decomposition of alumina hydrates. Microporous Mesoporous Mater 147(1):167-177. https://doi.org/10.1016/j. micromeso.2011.06.012

15. Kaur N, Ali A (2014) Kinetics and reusability of $\mathrm{Zr} / \mathrm{CaO}$ as a heterogeneous catalyst for the ethanolysis and methanolysis of Jatropha crucas oil. Fuel Process Technol 119:173-184. https:// doi.org/10.1016/j.fuproc.2013.11.002

16. Kaur N, Ali A (2015) Lithium zirconate as a solid catalyst for simultaneous esterification and transesterification of lowquality triglycerides. Appl Catal A 489:193-202. https://doi. org/10.1016/j.apcata.2014.10.013

17. Khosravi M, Baiyu M, Calvin H (2016) Synthesis and characterization of silica doped alumina catalyst support with superior thermal stability and unique pore properties. J Porous Mater 23(2):475-487. https://doi.org/10.1007/s10934-015-0101-z

18. Khosravi M, Lawson J, Huang B, Handly ED, Wood BF (2015) A statistical approach to control porosity in silica-doped alumina supports. Microporous Mesoporous Mater 210:116-124. https ://doi.org/10.1016/j.micromeso.2015.02.027

19. Kim H, Kang B, Kim M, Moo Y, Kim D, Lee J, Lee K (2004) Transesterification of vegetable oil to biodiesel using a heterogeneous base catalyst. Catal Today 95:315-320

20. Kim Y, Kim C, Kim P, Yi J (2005) Effect of preparation conditions on the phase transformation of mesoporous alumina. J NonCryst Solids 351:550-556. https://doi.org/10.1016/j.jnoncrysol .2005.01.009

21. Lesaint C, Kleppa G, Arla D, Glomm WR, Øye G (2009) Synthesis and characterization of mesoporous alumina materials with large pore size prepared by a double hydrolysis route. Microporous Mesoporous Mater 119(1-3):245-251. https://doi. org/10.1016/j.micromeso.2008.10.022

22. Li J, Wang T (2011) On the deactivation of alkali solid catalysts for the synthesis of glycerol carbonate from glycerol and dimethyl carbonate. React Kinet Mech Catal 102(1):113-126. https://doi. org/10.1007/s11144-010-0259-y
23. Liu Q, Wang A, Wang X, Zhang T (2006) Mesoporous Y-alumina synthesized by hydro-carboxylic acid as a structure-directing agent. Microporous Mesoporous Mater 92:10-21

24. Liu Q, Wang A, Wang X, Gao P, Wang X, Zhang T (2008) Synthesis, characterization, and catalytic applications of mesoporous $\mathrm{\gamma}$-alumina from boehmite sol. Microporous Mesoporous Mater 111(1-3):323-333. https://doi.org/10.1016/j.micro meso.2007.08.007

25. Liu Q, Wang L, Wang C, Qu W, Tian Z, Ma H, Wang D, Wang B, Xu $Z$ (2013) The effect of lanthanum doping on the activity of the Zn-Al spinel for transesterification. Appl Catal B 136-137:210217. https://doi.org/10.1016/j.apcatb.2013.01.065

26. Macina D, Piwowarska Z, Tarach K, Góra-marek K, Ryczkowski J, Chmielarz L (2016) Mesoporous silica materials modified with alumina polycations as catalysts for the synthesis of dimethyl ether from methanol. Mater Res Bull 74:425-435. https://doi. org/10.1016/j.materresbull.2015.11.018

27. Macquarrie DJ (2000) Chemistry on the inside : green chemistry in mesoporous materials. Phil Trans R Soc Land A 358:419-430

28. Márquez-Alvarez C, Žilková N, Pérez-Pariente J, Čejka J (2008) Synthesis, characterization and catalytic applications of organized mesoporous aluminas. Catal Rev 50(2):222-286. https://doi. org/10.1080/01614940701804042

29. Merino D, Perez-Miqueo I, Sanz O, Montes M (2016) On the way to a more open porous network of a Co- $\mathrm{Re} / \mathrm{Al}_{2} \mathrm{O}_{3}$ catalyst for fischer-tropsch synthesis : pore size and particle size effects on its performance. Top Catal 59:207-218. https://doi.org/10.1007/ s11244-015-0436-3

30. Naik, B., \& Ghosh, N. N. (2009). A review on chemical methodologies for preparation of mesoporous silica and alumina based materials. Recent Patents on Nanotechnology, 3(3), 213-224. http://www.ncbi.nIm.nih.gov/pubmed/19534702

31. Pan F, Lu X, Wang T, Wang Y, Zhang Z, Yan Y, Yang S (2013) Syn-

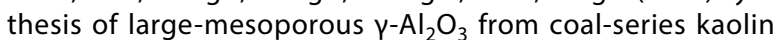
at room temperature. Mater Lett 91(1):136-138. https://doi. org/10.1016/j.matlet.2012.09.052

32. Pan F, Lu X, Wang T, Wang Y, Zhang Z, Yan Y (2013) Triton X-100 directed synthesis of mesoporous $\mathrm{Y}^{-} \mathrm{Al}_{2} \mathrm{O}_{3}$ from coal-series kaolin. Appl Clay Sci 85:31-38

33. Patel A, Brahmkhatri V (2013) Kinetic study of oleic acid esterification over 12-tungstophosphoric acid catalyst anchored to different mesoporous silica supports. Fuel Process Technol 113:141-149. https://doi.org/10.1016/j.fuproc.2013.03.022

34. Rouquerol F, Rouquerol J, Sing KS, Llewellyn P, Maurin G (2014) Adsorption by Powders and Porous Solids. Principles, Methodology and Application, vol 2. The Boulevard, Langford Lane, Kidlington, Oxford OX5 GB, UK Radarweg, p 29

35. Salahudeen N, Ahmed AS, Al-muhtaseb AH, Dauda M, Waziri SM, Jibril BY (2015) Synthesis of gamma alumina from Kankara kaolin using a novel technique. Appl Clay Sci 105-106:170-177

36. Samadhi TW, Lismana KR, Fuadi $\mathrm{K}$ (2011) Synthesis of $\mathrm{Y}-\mathrm{Al}_{2} \mathrm{O}_{3}$ Catalyst Support from Kaolin of Indonesian Origin. J Eng Sci 43:113-126

37. Sepehri S, Rezaei M, Garbarino G, Busca G (2016) Facile synthesis of a mesoporous alumina and its application as a support of Ni-based autothermal reforming catalysts. Int J Hydrogen Energy 41(5):3456-3464. https://doi.org/10.1016/j.ijhyd ene.2015.12.122

38. Shi Z, Jiao W, Chen L, Wu P, Wang Y, He M (2016) Clean synthesis of hierarchically structured boehmite and $\gamma$-alumina with a flower-like morphology. Microporous Mesoporous Mater 224:253-261. https://doi.org/10.1016/j.micromeso.2015.11.064 
39. Sun Z, Zheng T, Bo Q, Warren M (2008) Effects of alkali metal ions on the formation of mesoporous alumina. J Mater Chem 86:5941-5947. https://doi.org/10.1039/b810202c

40. Taufiq-Yap YH, Abdullah NF, Basri M (2011) Biodiesel production via transesterification of palm oil using $\mathrm{NaOH} / \mathrm{Al}_{2} \mathrm{O}_{3}$ catalysts. Sain Malaysiana 40:587-594

41. Valange S, Guth JL, Kolenda F, Lacombe S, Gabelica Z (2000) Synthesis strategies leading to surfactant-assisted aluminas with controlled mesoporosity in aqueous media. Microporous Mesoporous Mater 35-36:597-607. https://doi.org/10.1016/ S1387-1811(99)00253-X

42. Wan T, Yu P, Gong S, Li Q, Luo Y (2008) Application of KF/MgO as a heterogeneous catalyst in the production of biodiesel from rapeseed oil. Korean J Chem Eng 25(5):1363-1366. https://doi. org/10.1016/j.cclet.2011.05.041

43. Xie W, Li H (2006) Alumina-supported potassium iodide as a heterogeneous catalyst for biodiesel production from soybean oil. J Mol Catal A: Chem 255:1-9
44. Yang $\mathrm{H}$, Liu $\mathrm{M}$, Ouyang $\mathrm{J}$ (2010) Novel synthesis and characterization of nanosised $\gamma-\mathrm{Al}_{2} \mathrm{O}_{3}$ from kaolin. Appl Clay Sci 47:438-443

45. Zhang W, Zheng X, Zhao X, Zheng Y, Jiang L (2015) Carboxylic acid assisted synthesis of ordered mesoporous silicon-doped Y-alumina with high thermal stability. Mater Lett 160:85-87. https://doi.org/10.1016/j.matlet.2015.07.097

46. Zhao D, Wan Y, Zhou W Ordered Mesoporous Materials, vol 12. Wiley-VCH Verlag \& Co KGaA Boschstr, Weinheim, German, $\mathrm{p}$ 69469

47. Zhu HY, Riches JD, Barry JC (2002) Y-Alumina Nanofibers Prepared from Aluminum Hydrate with Poly (ethylene oxide) Surfactant. Chem Mater 14:2086-2093

Publisher's Note Springer Nature remains neutral with regard to jurisdictional claims in published maps and institutional affiliations. 